\title{
Article \\ Weight-Biased Language across 30 Years of Australian News Reporting on Obesity: Associations with Public Health Policy
}

\author{
Sharon Grant ${ }^{1}$, Arezou Soltani Panah ${ }^{2}\left(\mathbb{D}\right.$ and Anthony McCosker ${ }^{2, *}$ \\ 1 Department of Psychological Sciences, Swinburne University of Technology, Hawthorn, VIC 3122, Australia; \\ sgrant@swin.edu.au \\ 2 Social Innovation Research Institute, Swinburne University of Technology, Hawthorn, VIC 3122, Australia; \\ arezou.soltani@gmail.com \\ * Correspondence: amccosker@swin.edu.au; Tel.: +61-3-9214-4984
}

check for

updates

Citation: Grant, S.; Soltani Panah, A.; McCosker, A. Weight-Biased Language across 30 Years of Australian News Reporting on Obesity: Associations with Public Health Policy. Obesities 2022, 2, 103-114. https://doi.org/10.3390/ obesities 2010010

Academic Editors: Janet D. Latner, Kerry O'Brien and Angela Meadows

Received: 31 January 2022

Accepted: 23 February 2022

Published: 1 March 2022

Publisher's Note: MDPI stays neutral with regard to jurisdictional claims in published maps and institutional affiliations.

Copyright: (C) 2022 by the authors. Licensee MDPI, Basel, Switzerland. This article is an open access article distributed under the terms and conditions of the Creative Commons Attribution (CC BY) license (https:// creativecommons.org/licenses/by/ $4.0 /)$.
Abstract: (1) Background: This study tracked the reporting of obesity in the Australian news media over three decades and how changing representations over time were linked to obesity-related public health policy developments. (2) Methods: Machine learning and computational language analysis techniques (word embedding, dichotomous bias mapping) were used to identify language biases associated with obesity in 157,237 relevant articles drawn from the Australian Dow Jones digital database of print news media articles from 1990 to 2019. (3) Results: Obesity-related terms were stigmatised on four key dimensions (gender, health, socioeconomic status, stereotypes), with language biased towards femininity and lower socioeconomic status in particular. Biases remained relatively steady from 2005 to 2019, despite recent policy initiatives directly seeking to address obesity stigma. To some degree, for each of the four dimensions, cosine values moved toward 0 over time (i.e., no association with one dimension poll or the other), but remained around 0.20. There was a strong relationship between news media and public health policy discourse over the 30-year study period. (4) Conclusions: With increasing recognition of the health consequences of weight stigma, policymakers and the media must work together to ensure public weight management narratives avoid discourse that may stigmatise heavier individuals, particularly women, and/or reinforce negative obesity stereotypes.

Keywords: obesity; weight stigma; media analysis; language bias; natural language processing

\section{Introduction}

The framing of obesity in news media is an important issue for public health research due to long-standing obesity stigmatisation [1], which was identified as a significant barrier to obesity prevention and management [2]. For example, weight stigma was linked to negative body image, low self-esteem, binge eating, elevated blood pressure, unhealthy weight control behaviours, and depression [3]. The extent to which public attitudes about obesity are associated with news reporting of obesity is unclear [4]. As a staple of shareable public content $[5,6]$, news articles provide a consistent text dataset to track changes in the language through which people are likely to view public health issues. Using new computational language analysis techniques, it is now possible to show how obesity discourse has changed over several decades, embedding stigmatising concepts through associations with gender, healthiness, socioeconomic factors, and stereotypes. This has implications for the staging of public health interventions and weight management policy to reduce stigmatisation.

This article aims to identify changes in obesity framing over three decades by examining how national news coverage relates to major public health obesity policy developments. Our analysis begins in the 1990s, when national surveys of "Body Mass Index" (BMI), were introduced and significant increases in obesity rates were widely reported $[7,8]$, marking 
the onset of academic and professional agitation to include body weight on the public health agenda [8]. However, much has changed globally, and in Australia, in the way obesity has been addressed publicly since the 1990s. Accordingly, we examine changes in representations of obesity alongside key public health policy developments to contextualise and guide our analysis of the news dataset. Our work, which focuses on Australian news media, builds on recent studies that have sought to examine obesity framing in international media. For example, Nimegeer et al. [9] conducted a quantitative content analysis of childhood obesity framing in UK news across 19 years, focusing on 11 newspapers and 757 articles. Hamad et al. [10] analysed obesity descriptions and related policy proposals in 14,302 newspaper articles using an algorithm to automate document classification for content analysis. The authors utilised articles that mentioned the word "obesity" during 2011-2012 across four US states that vary in obesity prevalence and policy and described the reading and manual classification of massive volumes of articles as a "persistent dilemma" for investigators.

Improving on previous studies, we use machine learning and computational language analysis techniques to chart obesity representations in the Australian Dow Jones digital database of print news media articles from 1990 to 2019. Our ambitious approach applies word embedding analysis to a 30-year time period and a larger dataset (242,000 articles) than previous work and includes a range of obesity-related terms to improve the power, weight and certainty of our conclusions. We track associations of obesity with dimensions of gender, healthiness, social status, and obesity stereotypes over time. These dimensions capture social judgements of obesity from a range of perspectives that intersect with "weight stigma", or negative beliefs and attitudes about obesity [11]. For example, obesity has been equated with poor health [12], lower social status [13,14], and negative stereotypes [15]. In addition, women tend to be judged more harshly for their weight than men [16], thus it is of interest to examine whether the framing of obesity as a public health issue is gendered. These associations are not inherent characteristics of obesity itself, but rather indicate social perceptions of obesity produced in everyday interactions and institutions such as the government and media.

\section{Obesity Policy Timeline}

Table 1 summarises key obesity public health policy developments in Australia from 1990 to 2019. A review of policy documents shows major shifts throughout this time period. The time partitions provide indicators of the changes we would expect to see in news reporting. We expect to see a steady increase in obesity-related terms in the print news media from the 1990s, reflecting rising attention to obesity rates and advocacy around the need for action. Similarly, international attention to obesity was prompted by the World Health Organization's (WHO) consultations and major reports at the end of the 1990s and early 2000s. In 2000, the WHO released a report [17] on the global prevalence of obesity and a strategy for its prevention and management through public health policy and healthcare. By 2004, the WHO had released a global strategy to address non-communicable diseases that focused on two main risk factors, dietary intake and physical activity [18], perhaps unintentionally instigating the widely accepted "personal responsibility" narrative of obesity $[19,20]$. By the end of the early 2000s, there was a 10-fold increase in media stories on obesity around the world [11], popularising the "public health crisis" obesity narrative [21]. 
Table 1. Full timeline of obesity policy developments.

report [31] on the economic challenges of obesity. Weight stigma and lack of a collective critical barriers to action [2] 2017: PHAA releases a Health

2005: Australia's Department of

National BMI surveys introduced in Australia; significant increases in obesity rates.

Formation of Australasian

Society for the Study of Obesity

(ASSO; now the Australian and

New Zealand Obesity Society), a

member of the International

Association for the Study of

Obesity (IASO; now the World

Obesity Federation) [8].
1995: ASSO publishes an obesity policy advocacy document [22]

2000: WHO releases a report on the global prevalence of obesity and a strategy for its prevention and management [17]

2003: Australia's National

Obesity Taskforce for children

and adults releases a report

outlining a four-year

outlining a four-year agenda in$$
\text { to action to address }
$$
obesity-related

1998: The World Health
Organization's (WHO)

Consultation on Obesity provides a

of obesity on multiple

government agendas [8].

$$
\text { [24]. }
$$

2004: WHO releases a global

$$
\text { strategy to address }
$$

non-communicable diseases that focuses on two main risk factors, dietary intake and physical activity [18]. non-communicable diseases [23].

launching pad for the inclusion Health and Aging introduces an initiative [25] to address childhood obesity through infralia (PHAA) emerges as an influential obesity policy decade.

2010: Australian National

Preventive Health Agency

(ANPHA) is established to drive

health policies and programs,

2006: Royal Australian College of General Practitioners releases a policy to guide management of obesity in children and adults and Royal Children's Hospital releases a policy brief [26] to inform policy and practice regarding childhood obesity. 2008: Australian government's . releases a roadme for therce [8] [27]. strengthen preventive healt investment and infrastructure. 2012: PHAA introduces the Food, Nutrition and Health Policy [28]. 2014: ANPHA is consolidated within the Department of Health and with subsequent release of The Healthy Weight Guide [29], evidence-based, interactive website and print materials. Australian State governments and territories introduce Health
Public Health Association advocate, active throughout the

Levy on Sugar Sweetened Beverage

Policy [32] and Physical Activity Policy [33]

2018: WHO releases the Global Action Plan [34] on Physical Activity 2018-2030, including policy actions to increase physical activity and improve health outcomes, including obesity. Australia introduces the Food Policy Index to determine best Star Food Ratings [30]. practice for food and diet-related policies [35].

PHAA releases position

statements on the marketing of food and beverages to children [36] and nutrition monitoring and surveillance [37].

The Obesity Collective is

launched to address weight stigma and a collective voice for obesity [38].

2019: Australia's Department of Health introduces 24-h Movement Guidelines for physical exercise and sedentary behaviour [39]. PHAA calls for a revised, national and coordinated strateg

to address obesity [40]. 
Policy emphases in the early 2000s (2000-2004) are expected to coincide with an increased association between obesity and (poor) health and negative obesity stereotypes (e.g., lazy, weak-willed), emphasising the public health crisis and personal responsibility obesity narratives respectively, implicit in global obesity developments at the time. Likewise, childhood obesity, an emphasis in public health policy in the early 2000s, is expected to receive heightened attention in the print news media around this time. By the late 2000s (2005-2009), we expect to see an increased association between childhood obesity and health, families, and community/social factors, in line with policy emphases during this period.

From the 2010s onwards, public health policies considered a broader range of influences on weight, moving away from a predominant emphasis on dietary intake and physical activity (see Table 1). Attention to weight stigma also increased, especially in the latter part of this decade (2015-2019) [41], thus we expect to see a decreased association between obesity, negative obesity stereotypes, and (low) social status with time. The association of weight with gender, not evident in policy foci, is expected to remain relatively stable, in line with socio-cultural emphases on women's body weight [42] though this may decrease in the 2010s given an increased understanding of weight stigma and related attention to body size diversity.

This study addresses two research questions: (RQ1) How have associations of obesity with gender, healthiness, social status, and negative stereotypes changed over time? Additionally, (RQ2) Do changes in representations of obesity in the print news media correspond to changes in obesity-related public health policy over time?

\section{Materials and Methods}

To address our research questions, we adopted a novel methodology for quantifying the content of obesity-related language in news media, based on word embedding analysis (Word2Vec). Word embedding [43], is a neural network approach capable of learning distributed representations of words from a set of documents. It draws upon vector space mathematics to reveal hidden biases in language. Words from a text dataset are represented by a "dimensional vector", a language-based "schema" or representation of a concept. The geometric relationships between vector dimensions capture meaningful semantic associations between corresponding concepts. The method was used in various domains from bioinformatics [44] to public health research drawing insights from large text corpuses such as medical records [45]. Use of word embedding techniques to capture social and intersectional bias is gaining attention. Bolukbasi et al. [43], for example, used word embedding to examine the association between occupations and gender roles in Google News articles. More recently, Arseniev-Koehler et al. [46] used word embedding to extract cultural schemata about body weight from New York Times articles.

Extending these methods, we used the Word2Vec method to study changes in obesity framing in the Australian print news media from the 1990s to 2019. News articles were drawn from all national Australian news publishers and published articles (in print and online) since 1990, via the Application Programming Interface of the Dow Jones Data, News and Analytics (DNA) platform (https:/ /www.dowjones.com/news-you-can-use/, accessed on 9 May 2020).

A search strategy was devised to extract articles containing any of the following terms: Body Mass Index (BMI), body shape, body size, chubby, fat, flabby, obese, obesity, obesogenic, or overweight. Removal of duplicated/syndicated articles returned an initial sample of 242,000 articles. A random sample of 550 articles was manually evaluated by two researchers for relevance, to exclude articles using any of the terms with meanings unrelated to weight and obesity. This step determined that only $39 \%-48 \%$ of the search results were relevant ( $95 \%$ confidence interval). Due to dataset size, automated classification was used to assess relevance. Using the annotated samples as a training set, a supervised machine learning classifier called Support Vector Machine (https:/ /scikit-learn.org/stable/ 
modules/svm.html, accessed on 9 May 2021) was applied, and identified 157,237 relevant articles, with $87 \%$ training accuracy.

To extract a direction in semantic space corresponding to a specific dimension (e.g., gender), a set of anchor words is used that can represent the dimension. An anchor word should be paired to represent each end of the dimension. We refer to this step as dichotomous bias mapping. For the dimension of gender, the pair is "man, woman". This allows us to subtract the word-vector representing "masculine" from its "feminine" word-vector counterpart: woman - $\overrightarrow{m a n}$ (feminine vs. masculine dichotomy). In other words, assuming the meaning of man and woman are largely equivalent except for their gender component, the subtraction cancels out all but the gender differences across each dimension. In the geometric space, the resulting vector can be construed as an axis ranging from -1 (hyper-masculinity) to 1 (hyper-femininity) with gender-neutral at 0 .

We generated four dichotomous dimensions: gender, healthiness, socioeconomic status, and stereotypes in the manner described above. For gender, anchor words were selected from the published lexicon used by Bolukbasi et al. [43]. Additional terms were added that represented gendered parenting such as (mothers, fathers), (maternity, paternity), and (motherhood, fatherhood). Anchor words for healthiness and social status were collated from an established source to compare individual versus structural determinants of obesity [46]. Examples of healthiness anchor words are (healthy, unhealthy), (nutritious_foods, junk_foods), and (exercise, sedentary). For socioeconomic status, examples are (wealth, poverty), (educated, uneducated), and (employed, unemployed). For stereotypes, we compiled a list of anchor words from the Implicit Association Test and the Obesity Persons Trait survey reflecting common obesity stereotypes $[47,48]$. Word pair examples include (generous, gluttonous), (self-indulgent, restrained), and (disciplined, undisciplined).

Finally, the relationships between obesity-related terms and the four dimensions were measured with cosine similarity values which range from -1.00 to 1.00 . Similarity is measured by subtracting the average of cosine similarity between the dichotomous concepts (e.g., men, women). For instance, if the obesity vector is close to women, it does not suggest bias by itself, but the fact that the distance is not equal to men reveals bias. The polarity of cosine metric represents the semantic association (geometric bias), whereas its magnitude shows the degree of semantic association between dimensions.

\section{Results}

In this section, we show the associations between obesity-related terms and the gender, healthiness, social status, and stereotype dimensions. These associations are subsequently cross-matched with the obesity policy timeline in the Discussion, to help interpret the context of change in biases over time. Figure $1 \mathrm{a}-\mathrm{d}$ present the average cosine similarity of obesity-related words with respect to a given dimension.

The first dimension captured the archetypical concept for gender, ranging from masculine to feminine. As Figure 1a shows, there is a clear relationship between obesity-related terms and gender, with most terms being feminised. Obesity, overweight, and excess weight generally showed the strongest association with femininity, particularly in the early 1990s, but this decreased over time. BMI did not appear to emerge until the mid-1990s and from then it was mostly associated with femininity and this was relatively stable over time. Childhood obesity emerged in the 2000s and its association with femininity increased over time. Notably "femininity" includes gendered parenting terms, with the results showing that childhood obesity is associated with maternal parenting.

Second, Figure $1 \mathrm{~b}$ illustrates the relationship between obesity-related terms and healthiness over time. Obesity-related terms were associated more with healthiness from 1990-1999. From 2000 onwards, however, these terms showed a marked change, becoming increasingly associated with being unhealthy. 


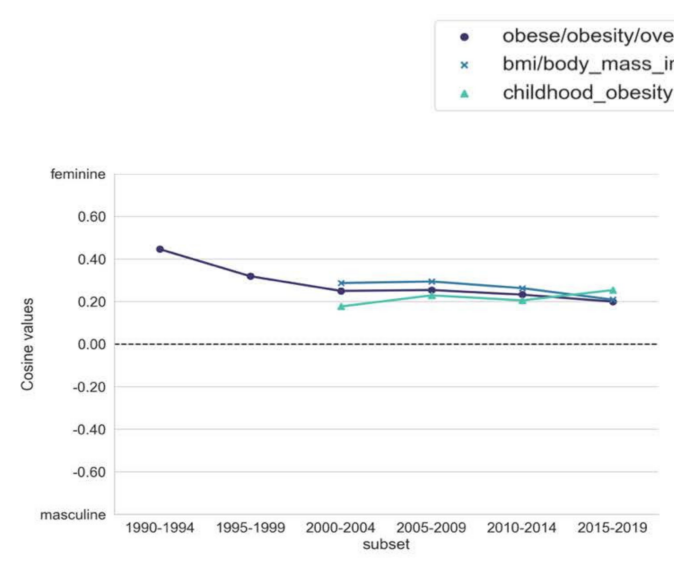

(a)

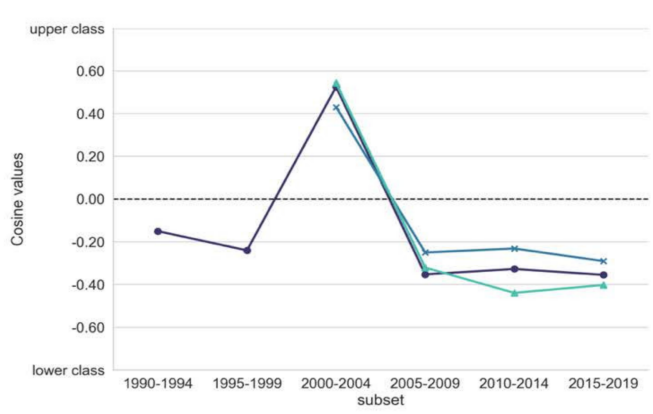

(c)

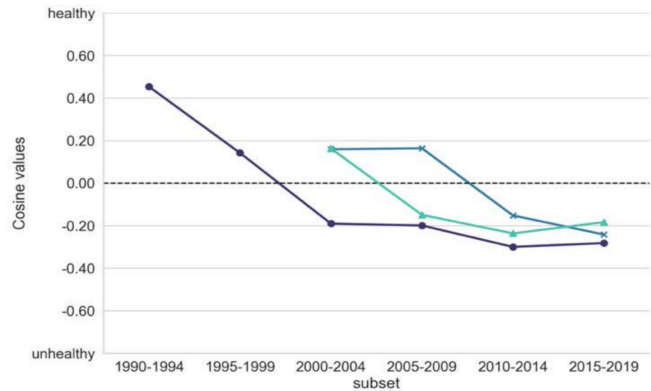

(b)

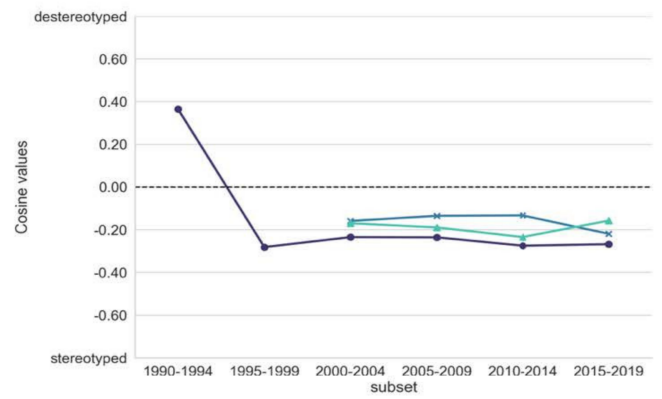

(d)

Figure 1. Cosine similarity between obesity-related terms and (a) gender (b) healthiness (c) social status and (d) stereotype dimensions.

Third, Figure 1c captures the relationship between obesity-related terms and socioeconomic status over time. Obesity-related terms were associated with the highest SES (cosine similarity close to 0.60 ) during 2000-2004 with a sharp decrease (lower SES) from 2005, particularly for childhood obesity.

Lastly, Figure $1 \mathrm{~d}$ shows the relationship between obesity-related terms and stereotypes over time. A broad observation is that obesity-related terms connote stereotyping. Notably, during 1990-1994, terms such as obesity or being overweight were "de-stereotyped" (cosine similarity close to 0.40), but this changed from 1995 onwards and remained relatively stable thereafter, suggesting that obesity has been negatively stereotyped since it arose on the public health agenda in the late 1990s. Childhood obesity was less stigmatised than obesity and its stigmatisation has decreased recently.

\section{Discussion}

RQ1 considered semantic associations with obesity in the news and their change over time. This was examined by calculating the cosine values of obesity-related terms for four key dimensions. RQ2 asked whether these changes correspond to major developments in obesity-related public health policy over the same timeframe. Word embedding analysis revealed semantic changes over time. On each dimension-gender, healthiness, social status, and stereotypes-obesity-related terms were stigmatised and biased toward the feminine and low socioeconomic language in particular. These biases remain relatively steady from around 2005 to 2019, despite policy initiatives in the last five years more directly addressing obesity stigma. Such entrenched weight biases, persistent in the media, may lead to internalised or self-stigma among individuals with obesity that persist even after weight loss. A recent study [49] performed a semantic evaluation of body shapes in obesity surgery patients and overweight/obesity controls and found that both groups were more 
willing to accept positive adjectives as a match when BMI was low and negative adjectives as a match when BMI was high.

Next, we break down these findings further to examine their relationship with public health policy discourses of obesity. Childhood obesity was emphasised in Australian public health policy in the early 2000s, with the National Obesity Taskforce releasing a four-year agenda in 2003 [24]. A policy to guide the management of obesity in children and adults by general practitioners was released by the Royal Australian College of General Practitioners in 2006 [50], and the Royal Children's Hospital also released a policy brief regarding childhood obesity around this time [26]. Consistent with this, our results indicated that childhood obesity, absent in the news in the early 1990s, emerged from the 2000s. From the time it appeared, childhood obesity was consistently associated with femininity and generally showed an increasing relationship with femininity over time. This may suggest that maternal parenting was implicated in childhood obesity in the media, possibly due to child-focused policies at the time, as our feminine dimension included female parenting terms. However, the relationship of childhood obesity to feminine versus masculine parenting terms was not examined separately. Accordingly, it is unclear whether childhood obesity showed an association with all feminine descriptors or only feminine parenting descriptors.

The results indicated that obesity-related terms were generally associated with healthiness in the 1990s but that this showed a marked change from the 2000s, with heaviness becoming increasingly associated with being "unhealthy" and with unhealthy lifestyles. The trend was similar for childhood obesity, in which unhealthy lifestyles are predominantly attributed to parents for failing to foster healthy behaviours in their children. Political action on obesity during the 1990s was generally slow [8]. In 1995, the Australasian Society for the Study of Obesity (ASSO; now the Australian and New Zealand Obesity Society), a member of the International Association for the Study of Obesity (IASO; now the World Obesity Federation) published a policy advocacy document [22] that motivated the National Health and Medical Research Council (NHRMC) report, Acting on Australia's Weight, a call to action to address obesity-related non-communicable diseases such as diabetes mellitus [23]. However, the recommendations from this report, which focused on diet and exercise, were not embedded in public health policy at this time. A critical turning point for obesity-related public health policy was the 1998 IASO-initiated inaugural WHO Consultation on Obesity, which provided a launching pad for the inclusion of obesity on multiple government agendas [8]. Policy emphases in the early 2000s (2000-2004; see Table 1) are consistent with the increased association between obesity and (poor) health observed in our results, reflecting the public health crisis or "obesity epidemic" narrative implicit in global obesity developments at the time.

The dimension of socioeconomic status points more directly to social or structural aspects of obesity, and this is reflected in policy targets. Our findings show that obesity was associated with socioeconomic disadvantage from the mid-2000s. Notably, obesity-related terms connoted higher SES during 2000-2004, but there was a sharp decrease from 2005, particularly for childhood obesity. Thus, our findings reflect an increased association between obesity and families and community/social factors in the media, consistent with the policy emphases at the time (see Table 1). In 2005, an Australian Department of Health and Aging initiative [25] was introduced to address obesity through healthy school communities, healthy families, active school curricula, and active after-school communities. By the 2010s, policy initiatives underscored the need to provide healthy, affordable, and acceptable food to all Australians. In 2010, the Australian National Preventive Health Agency was established to drive preventive health policies and programs, and strengthen preventive health investment and infrastructure. However, by 2014 this agency was consolidated within the Department of Health [29]. Public Health Association Australia (PHAA) subsequently emerged as an influential policy advocate in this decade, introducing several policies in the 2010s, including the Food, Nutrition and Health Policy [28] in 2012, and the 
Health Levy on Sugar-Sweetened Beverage Policy [32] and the Physical Activity Policy [33] in 2017.

Policy emphases in the early 2000s (2000-2004) were expected to coincide with an increased association between obesity and negative obesity stereotypes, reflecting the public health crisis and personal responsibility obesity narratives implicit in global obesity developments at the time. Perpetuation of the notion that obesity equates to disease and is driven by individual-level factors (e.g., overeating, laziness) reinforces stigma. Negative stereotyping of obesity emerged slightly earlier than expected: our results showed that terms such as obesity or being overweight were destigmatised from 1990 to 1994, but this changed from the mid-1990s onwards.

In 2007, overweight and obesity rates reached $61 \%$ of all Australian adults [51]. The same year, the UK government's Foresight Report [36], presented an influential "spaghetti map", representing obesity as a complex problem driven by an obesogenic environment, and emphasising the need for systems approaches. After Foresight, there was strong scientific consensus that obesity initiatives needed to move upstream, to factors largely outside individual control [52]. Thus, we expected to see a reduction in negative stereotypes of obesity from the late 2000s. Contrary to expectation, obesity and being overweight were consistently negatively stereotyped over time in our dataset. Childhood obesity was also negatively stereotyped, but less so than obesity generally, and this stereotyping has decreased recently. This may reflect increased awareness of the role of societal factors, and especially the food industry (e.g., advertising) in childhood obesity. Even BMI, regarded as a weight-neutral term, was associated with negative stereotypes, which may reflect recognition of BMI as a widely used index of obesity.

The late 2000s saw increased attention to weight stigma. In particular, the work of Rebecca Puhl of the Rudd Center for Food Policy and Obesity, became influential in the U.S, with a proliferation of publications [41]. However, the recognition of weight stigma in other parts of the world, including Australia, happened slowly. In 2015, a report by Obesity Australia and $\mathrm{PwC}$ [31] acknowledged that current interventions were inadequate for meeting the (WHO) target of halting obesity rates by 2025 and concluded that innovative approaches to prevention and relapse are needed. The report initiated a series of roundtable discussions, and weight stigma and the lack of a collective voice for individuals with obesity were identified as critical barriers to action [2]. In 2018, the Obesity Collective was launched to address these barriers [38]. We expected to see some shift in news framing of obesity associated with these developments in the last five years, but this was not evident. In 2017-2018, overweight/obesity in adults surpassed more than two-thirds of Australian adults [53] and reached almost a quarter of Australian children aged 5-17 [54]. Despite increased recognition of weight stigma, it has not decreased. In fact, societal shifts in attitudes and related biases (e.g., negative stereotypes) can be slow to change [55], particularly if left unchallenged in weight-related public health campaigns [56]. In 2019, the PHAA called for a revised, national and coordinated plan to address obesity [40]. A National Obesity Summit was held in February 2019 to identify priority areas for inclusion in the Strategy. Thus, expected changes might be evident in the future, most likely in the next five-year time period. This highlights the need for continuing discourse analysis.

\section{Limitations and Future Research}

We acknowledge that there are limitations in our data curation process. Firstly, automatic classifiers of any sort, such as the ones we used to check and select papers, can include some irrelevant or false positive articles. Due to the large number of articles in our dataset, as part of our methodology we developed a machine learning binary classifier-a support vector machine-with $87.56 \%$ accuracy to automatically identify relevant articles (here, accuracy is defined as the number of correct predictions made, divided by the total number of predictions made, then multiplied by 100 to convert it to a percentage). As a rule of thumb, the accuracy of a predictive model that is above $80 \%$ is very commonly used to summarise the performance of that model. Still, it does not exclude the possibility of 
irrelevant articles in our final dataset. Nonetheless, that possibility is less than $12.44 \%$ and this has to be considered against the benefit of the scale and efficiency that this method allows.

We also acknowledge that our analysis is limited in not being able to consider visual content or images within articles (known as image framing), which was shown to carry stigmatising elements [56]. This is something that could be added to the approach by including image classification along with additional measures. Furthermore, even though the Dow Jones is one the largest news databases, it might still miss some articles or news sources. This applies to social media, although this would not span as long a timeframe.

Although the research has limitations, it also offers directions for future research, which could address visual and social media elements more directly. In addition, there is an opportunity in future analyses to more clearly differentiate health/fitness and exercise, currently both included in our "healthiness" dimension. Likewise, in line with specific policy issues, the inclusion of dimensions targeting race and ethnicity could build on existing research with a focus, for example, on Indigenous health [57]. It is also important to examine relationships between news media reporting of obesity and mental health outcomes over time given, for example, medium to large meta-analytic associations between weight stigma and mental health disorders such as anxiety, depression, eating disorders, and other psychopathological symptoms [58]. Future research could also extend our word embedding analysis to policy texts themselves, to draw direct correlations between media and policy data sources. Although based on a restricted area of exploration, Australian print news media only, our findings may have much broader significance for worldwide social trends and prompt the need for ongoing analysis of media reporting of obesity and weight-related public health policy.

\section{Conclusions}

Our longitudinal word embedding analysis revealed a pattern of slow-paced shifting from individual obesity frames to more structural obesity frames, suggesting an inclination towards regulatory changes in public discourse over recent years. If internalised by the public, the predominance of social frames over individual ones could result in a decrease in weight stigma over time. Despite the shift in the presentation of causes and solutions for obesity in recent media, the majority of government activities presented in our policy timeline have focused on community education (e.g., nutrition guidelines for children and adults), rather than legislation (food taxation and marketing laws). To accelerate change, the government and media need to work in tandem to develop policies and messages to reduce weight stigma and promote healthy behaviour change.

Author Contributions: S.G.: Conceptualization (30\%); Data curation (15\%); Formal analysis (20\%); Funding acquisition ( $0 \%$ ); Investigation (30\%); Methodology (30\%); Project administration (10\%); Resources (20\%); Software (0\%); Supervision (30\%); Validation (25\%); Visualization (5\%); Roles/Writingoriginal draft (50\%); Writing-review and editing (50\%). A.S.P.: Conceptualization (20\%); Data curation (70\%); Formal analysis (60\%); Funding acquisition (40\%); Investigation (40\%); Methodology $(40 \%)$; Project administration (10\%); Resources (40\%); Software (100\%); Supervision (40\%); Validation (50\%); Visualization (90\%); Roles/Writing—original draft (10\%); Writing-review and editing (5\%). A.M.: Conceptualization (30\%); Data curation (15\%); Formal analysis (20\%); Funding acquisition (60\%); Investigation (30\%); Methodology (30\%); Project administration (80\%); Resources (40\%); Software $(0 \%)$; Supervision (30\%); Validation (25\%); Visualization (5\%); Roles/Writing—original draft $(40 \%)$; Writing-review and editing (45\%). All authors have read and agreed to the published version of the manuscript.

Funding: This work was funded by the Victorian Health Promotion Foundation (VicHealth).

Institutional Review Board Statement: Not applicable.

Informed Consent Statement: Not applicable. 
Data Availability Statement: This study is based on Dow Jones content available via the Factiva Analytics platform found at: https:/ / professional.dowjones.com/advanced-analytics-data-mining/ (accessed on 9 May 2020).

Acknowledgments: We acknowledge the contributions of Nithya Solomon and Kristen MoellerSaxone to this project.

Conflicts of Interest: The authors declare no conflict of interest.

\section{References}

1. Atanasova, D.; Koteyko, N.; Gunter, B. Obesity in the news: Directions for future research. Obes. Rev. 2012, 13, 554-559. [CrossRef]

2. History of the Collective. Available online: http:/ / www.obesityaustralia.org/history (accessed on 9 May 2021).

3. Puhl, R.M.; Suh, Y. Health Consequences of Weight Stigma: Implications for Obesity Prevention and Treatment. Curr. Obes. Rep. 2015, 4, 182-190. [CrossRef] [PubMed]

4. Liu, J.; Lee, B.; McLeod, D.M.; Choung, H. Framing Obesity: Effects of Obesity Labeling and Prevalence Statistics on Public Perceptions. Health Educ. Behav. 2019, 46, 322-328. [CrossRef] [PubMed]

5. Kümpel, A.S.; Karnowski, V.; Keyling, T. News sharing in social media: A review of current research on news sharing users, content, and networks. Soc. Media Soc. 2015, 1, 2056305115610141. [CrossRef]

6. Hurcombe, E.; Burgess, J.; Harrington, S. What's newsworthy about 'social news'? Characteristics and potential of an emerging genre. Journalism 2019, 22, 378-394. [CrossRef]

7. Nuttall, F.Q. Body mass index: Obesity, BMI, and health: A critical review. Nutr. Today 2015, 50, 117. [CrossRef]

8. Swinburn, B.; Wood, A. Obesity prevention in Australia and New Zealand. Obes. Rev. 2013, 14, 60-68. [CrossRef]

9. Nimegeer, A.; Patterson, C.; Hilton, S. Media framing of childhood obesity: A content analysis of UK newspapers from 1996 to 2014. BMJ Open 2019, 9, e025646. [CrossRef]

10. Hamad, R.; Pomeranz, J.L.; Siddiqi, A.; Basu, S. Large-scale automated analysis of news media: A novel computational method for obesity policy research. Obesity 2014, 23, 296-300. [CrossRef]

11. Puhl, R.M.; Moss-Racusin, C.A.; Schwartz, M.B.; Brownell, K.D. Weight stigmatization and bias reduction: Perspectives of overweight and obese adults. Health Educ. Res. 2007, 23, 347-358. [CrossRef]

12. Tylka, T.L.; Annunziato, R.A.; Burgard, D.; Daníelsdóttir, S.; Shuman, E.; Davis, C.; Calogero, R.M. The Weight-Inclusive versus Weight-Normative Approach to Health: Evaluating the Evidence for Prioritizing Well-Being over Weight Loss. J. Obes. 2014, 2014, 983495. [CrossRef] [PubMed]

13. Puhl, R.M.; Heuer, C.A. Obesity Stigma: Important Considerations for Public Health. Am. J. Public Health 2010, 100, 1019-1028. [CrossRef] [PubMed]

14. Vartanian, L.R.; Silverstein, K.M. Obesity as a status cue: Perceived social status and the stereotypes of obese individuals. J. Appl. Soc. Psychol. 2013, 43, E319-E328. [CrossRef]

15. Grant, S.; Mizzi, T. Body weight bias in hiring decisions: Identifying explanatory mechanisms. Soc. Behav. Pers. 2014, 42, 353-370. [CrossRef]

16. Puhl, R.M.; Andreyeva, T.; Brownell, K.D. Perceptions of weight discrimination: Prevalence and comparison to race and gender discrimination in America. Int. J. Obes. 2008, 32, 992-1000. [CrossRef]

17. World Health Organization. Obesity: Preventing and Managing the Global Epidemic; World Health Organization: Geneva, Switzerland, 2000 .

18. World Health Organization. Global Strategy on Diet, Physical Activity and Health; World Health Organization: Geneva, Switzerland, 2004.

19. Farrell, L.C.; Warin, M.J.; Moore, V.M.; Street, J.M. Socio-economic divergence in public opinions about preventive obesity regulations: Is the purpose to 'make some things cheaper, more affordable' or to 'help them get over their own ignorance'? Soc. Sci. Med. 2016, 154, 1-8. [CrossRef]

20. Thompson, L.; Kumar, A. Responses to health promotion campaigns: Resistance, denial and othering. Crit. Public Health 2011, 21, 105-117. [CrossRef]

21. O'Hara, L.; Gregg, J. Human Rights Casualties from the "War on Obesity": Why Focusing on Body Weight Is Inconsistent with a Human Rights Approach to Health. Fat Stud. 2012, 1, 32-46. [CrossRef]

22. Thomas, M.; Wise, M. Healthy Weight Australia: A National Obesity Strategy; Australasian Society for the Study of Obesity: Canberra, Australia, 1995.

23. National Health and Medical Research Council. Acting on Australia's Weight: A Strategic Plan for the Prevention of Overweight and Obesity; NHMRC: Canberra, Australia, 1997.

24. National Obesity Taskforce. Healthy Weight 2008: Australia's Future: The National Action Agenda for Children and Young People and Their Families; National Obesity Taskforce: Canberra, Australia, 2003.

25. Department of Health and Ageing. Building a Healthy, Active Australia; Department of Health and Ageing: Canberra, Australia, 2005.

26. Royal Children's Hospital. Policy Brief: Translating Early Childhood Research Evidence to Inform Policy and Practice: Overweight and Obesity in Childhood; RCH: Melbourne, Australia, 2007. 
27. National Preventative Health Taskforce. Australia: The Healthiest Country by 2020; Commonwealth of Australia: Canberra, Australia, 2009.

28. Public Health Association Australia. Policy-at-a-Glance-Food, Nutrition, and Health Policy. September 2021. Available online: https:/ / www.phaa.net.au/documents/item/213 (accessed on 9 May 2021).

29. Department of Health. The Healthy Weight Guide; Commonwealth of Australia: Canberra, Australia, 2014. Available online: http:/ / healthyweight.health.gov.au/ (accessed on 9 May 2021).

30. Commonwealth of Australia. Health Star Rating System; Commonwealth of Australia: Canberra, Australia, 2014. Available online: http:/ / www.healthstarrating.gov.au/internet/healthstarrating/publishing.nsf/Content/About-health-stars (accessed on 20 May 2020).

31. PricewaterhouseCoopers. Weihing the Cost of Obesity: A Case for Action; PricewaterhouseCoopers: Sydney, Australia, October 2015. Available online: https:/ / www.pwc.com.au/pdf/weighing-the-cost-of-obesity-final.pdf (accessed on 9 May 2021).

32. Public Health Association Australia. Policy-at-a-Glance-Health Levy on Sugar Sweetened Beverage Position Statement. October 2017. Available online: https:/ / www.phaa.net.au/documents/item/2483 (accessed on 9 May 2021).

33. Public Health Association Australia. Policy-at-a-Glance-Physical Activity Policy. October 2017. Available online: https: //www.phaa.net.au/documents/item/2555 (accessed on 9 May 2021).

34. World Health Organization. Action Plan on Physical Activity 2018-2030: More Active People for a Healthier World; WHO: Geneva, Switzerland, 2018. Available online: https:/ /apps.who.int/iris/bitstream/handle/10665/272722/9789241514187-eng.pdf?ua=1 (accessed on 20 May 2020).

35. The Australian Prevention Partnership Centre, Deakin University Australia, Informas. Policies for Tackling Obesity and Creating Healthier Food Environments: 2019 Progress Update Australian Governments. March 2019. Available online: https: / / 6caf7727-1efc-419a-8b13-d58f79d7351f.filesusr.com/ugd/2e3337_5d2fdb48e7114f2c8cd14e79cb194393.pdf (accessed on 20 May 2020).

36. Government Office for Science. Obesity System Map; Foresight: London, UK, 2007. Available online: https://assets.publishing service.gov.uk/government/uploads/system/uploads/attachment_data/file/295153/07-1177-obesity-system-atlas.pdf (accessed on 9 May 2021).

37. Health Association Australia. Food and Nutrition Monitoring and Surveillance in Australia: Policy Position Statement; Public Health Association Australia: Canberra, Australia, 26 September 2018. Available online: https://www.phaa.net.au/documents/item/28 66 (accessed on 20 May 2020).

38. The Obesity Collective. Available online: http:/ / www.obesityaustralia.org/ (accessed on 9 May 2021).

39. Department of Health. Australia's Physical Activity and Sedentary Behaviour Guidelines and the Australian 24 h Movement Guidelines; Australian Government Department of Health: Canberra, Australia, 12 April 2019. Available online: https://www1.health.gov. au/internet/main/publishing.nsf/Content/health-pubhlth-strateg-phys-act-guidelines\#npa05 (accessed on 20 May 2020).

40. Public Health Association Australia. Prevention and Management of Overweight and Obesity in Australia: Policy Position Statement; PHAA: Deakin, Australia, September 2019. Available online: https://www.phaa.net.au/documents/item/3794 (accessed on 9 May 2020).

41. Faculty and Staff: Rebecca Puhl, PHD. Available online: https://uconnruddcenter.org/person/rebecca-puhl/ (accessed on 12 June 2020).

42. Ata, R.N.; Thompson, J.K. Weight Bias in the Media: A Review of Recent Research. Obes. Facts 2010, 3, 41-46. [CrossRef]

43. Bolukbasi, T.; Chang, K.W.; Zou, J.; Saligrama, V.; Kalai, A. Man is to computer programmer as woman is to homemaker? debiasing word embeddings. arXiv 2016, arXiv:1607.06520.

44. Hamid, M.-N.; Friedberg, I. Identifying antimicrobial peptides using word embedding with deep recurrent neural networks. Bioinformatics 2019, 35, 2009-2016. [CrossRef] [PubMed]

45. Lin, C.; Lou, Y.-S.; Tsai, D.-J.; Lee, C.-C.; Hsu, C.-J.; Wu, D.-C.; Wang, M.-C.; Fang, W.-H. Projection Word Embedding Model with Hybrid Sampling Training for Classifying ICD-10-CM Codes: Longitudinal Observational Study. JMIR Med Informatics 2019, 7, e14499. [CrossRef] [PubMed]

46. Arseniev-Koehler, A.; Foster, J.G. Machine learning as a model for cultural learning: Teaching an algorithm what it means to be fat. arXiv 2020, arXiv:2003.12133.

47. Teachman, B.; Brownell, K. Implicit anti-fat bias among health professionals: Is anyone immune? Int. J. Obes. 2001, 25, 1525-1531. [CrossRef] [PubMed]

48. Puhl, R.M.; Schwartz, M.B.; Brownell, K.D. Impact of Perceived Consensus on Stereotypes About Obese People: A New Approach for Reducing Bias. Health Psychol. 2005, 24, 517-525. [CrossRef] [PubMed]

49. Meneguzzo, P.; Behrens, S.C.; Favaro, A.; Tenconi, E.; Vindigni, V.; Teufel, M.; Skoda, E.-M.; Lindner, M.; Quiros-Ramirez, M.A.; Mohler, B.; et al. Body Image Disturbances and Weight Bias after Obesity Surgery: Semantic and Visual Evaluation in a Controlled Study, Findings from the BodyTalk Project. Obes. Surg. 2021, 31, 1625-1634. [CrossRef]

50. Royal Australian College of General Practitioners. Overweight and Obesity: Policy Endorsed by the 48th RACGP Council 26 July 2006; RACGP: Melbourne, Australia, 2006.

51. Public Health Association Australia. Marketing of Food and Beverages to Children: Policy Position Statement. 26 September 2018. Available online: https:/ /www.phaa.net.au/documents/item/2867 (accessed on 9 May 2021). 
52. Finegood, D.T.; Karanfil, O.; Matteson, C.L. Getting from analysis to action: Framing obesity research, policy and practice with a solution-oriented complex systems lens. Healthc. Pap. 2008, 9, 36-41. [CrossRef]

53. Australian Bureau of Statistics. Overweight and Obesity; Australian Bureau of Statistics: Canberra, Australia, 7 February 2018. Available online: https:/ /www.abs.gov.au/ausstats/abs@.nsf/Lookup/by\%20Subject/4364.0.55.001 2017-18 Main\%20Features Overweight \%20and\%20obesity 90 (accessed on 9 May 2020).

54. Australian Institute of Health and Welfare. Overweight and Obesity: An Interactive Insight. 19 June 2019. Available online: https:/ / www.aihw.gov.au/reports / overweight-obesity / overweight-and-obesity-an-interactive-insight/contents/whatis-overweight-and-obesity (accessed on 9 May 2020).

55. Grant, S.L.; Mizzi, T.; Anglim, J. 'Fat, four-eyed and female'30 years later: A replication of Harris, Harris, and Bochner's (1982) early study of obesity stereotypes. Aust. J. Psychol. 2016, 68, 290-300. [CrossRef]

56. Johnstone, G.; Grant, S.L. Weight stigmatisation in antiobesity campaigns: The role of images. Health Promot. J. Aust. 2019, 30, 37-46. [CrossRef]

57. Islam, S.; Fitzgerald, L. Indigenous obesity in the news: A media analysis of news representation of obesity in Australia's Indigenous population. BMC Obes. 2016, 3, 30. [CrossRef]

58. Emmer, C.; Bosnjak, M.; Mata, J. The association between weight stigma and mental health: A meta-analysis. Obes. Rev. 2020, 21, e12935. [CrossRef] [PubMed] 